\title{
Retroperitoneal Schwannoma: A Case Report and Review of the Literature
}

\author{
ASMZ RAHMAN $^{\mathrm{a}}$, CK GHOSH ${ }^{\mathrm{b}}$, ZR SHARMIN ${ }^{\mathrm{c}}$
}

\begin{abstract}
Summary:
A 45 years old woman admitted to our Hospital with pain in the right flank and right hypochondrium. Her abdominal USG and CT scan showed a large complex cystic mass present in the deep soft tissue compressing the right kidney. Multiple gall bladder stones were also found in imaging. Both the adrenal glands and left kidney had a normal appearance.
\end{abstract}

\section{Introduction:}

Schwannoma is also called neurilemmoma, is a tumor originating from the Schwann's cells derived from the neuroectoderm. In 1980, Verocay reported for the first time a tumor that occurred in the neurons histologically ${ }^{1}$. Masson has described that these tumors arise from Schwann's cells and are termed as schwannoma ${ }^{2}$.

Most schwannomas are benign, though malignant schwannomas are usually seen associated with Von Recklinghausen's disease ${ }^{3}$. The majority of the schwannomas arise from Schwann cells of peripheral nerve fibers and are usually located in the head, neck and flexore surface of the extremities, but rarely they can arise from mediastinum and retroperitoneum ${ }^{4,5,6,7}$. Urinary tract is seldom involved, most commonly testis, penis, spermatic cord, and tunica vaginalis ${ }^{8,9,10}$. The majority of retroperitoneal schwannomas are benign in nature although malignant ones have also been reported. Most common presentation of the retroperitoneal

a. Prof. Dr. A.S.M Zahidur Rahman, Professor and Head, Department of Surgery, City Medical College \& Hospital, Gazipur, Dhaka.

b Dr. Chanchal Kumar Ghosh, Asst. Professor, Gastroenterology, BSMMU.

c. Dr. Zinat Rehana Sharmin, Assistant Professor, Dept. of Pharmacology, Uttara Adhunik Medical College, Uttara Dhaka.

Address of Correspondence: Prof. Dr. A.S.M Zahidur Rahman, Professor and Head, Department of Surgery, City Medical College \& Hospital, Gazipur, Dhaka, Mobile: 01714093604, Email: asmrahman@gmail.com

Received: 1 April, 2014

Accepted: 29 April, 2015
The mass was completely resected with extended right subcostal incision along with excision of Gall bladder.

Histopathological examination of the specimen revealed a degenerated schwannoma. Patient was discharged on $8^{\text {th }}$ day after operation without any complications.

Key words: Retroperitoneal Schwannoma, Flank pain.

(J Banagladesh Coll Phys Surg 2015; 33: 225-228)

schwannoma is abdominal distention with vague or dull abdominal ache $e^{4,10}$.

We report on a case with benign retroperitoneal schwannoma and describe the diagnostic and management options.

\section{Case Reports:}

A 45 years old woman was admitted with pain and a palpable mass in her right flank. She had no history of fever, weight loss or anorexia. On abdominal examination, a large retroperitoneal lump measuring about $15 \mathrm{~cm} \mathrm{x}$ $10 \mathrm{~cm}$ was found in the right hypochondriac region extending into the right lumber region with a smooth surface, firm in consistency and non palsatile. Examination of other systems and routine laboratory parameter were within normal limits.

Ultrasonography ( USG) showed a well define complex cystic mass in the right retroperitoneal region pushing the right kidney anteriorly and medially. An incidental findings of cholelithiasis was also found. There was multiple small bright echogenic structure in the gall bladder. Intrahepatic and extrahepatic biliary try was not dilated.

Computed tomography scan( CT scan) showed a sharply demarcated hypodense mass located just lateral and posterior to the right kidney. (Fig.-1)

In preoperative period we did not take CT guided biopsy, because we don't have this facilities in our institution and patient was unable due to poor economic condition and possibility of adrenal tumor kept in mind. The patient was worked up for surgery.

Abdomen was opened with extended right subcostal incision, the abdomen was explored. Cholelithiasis was found and cholecystectomy was done. 


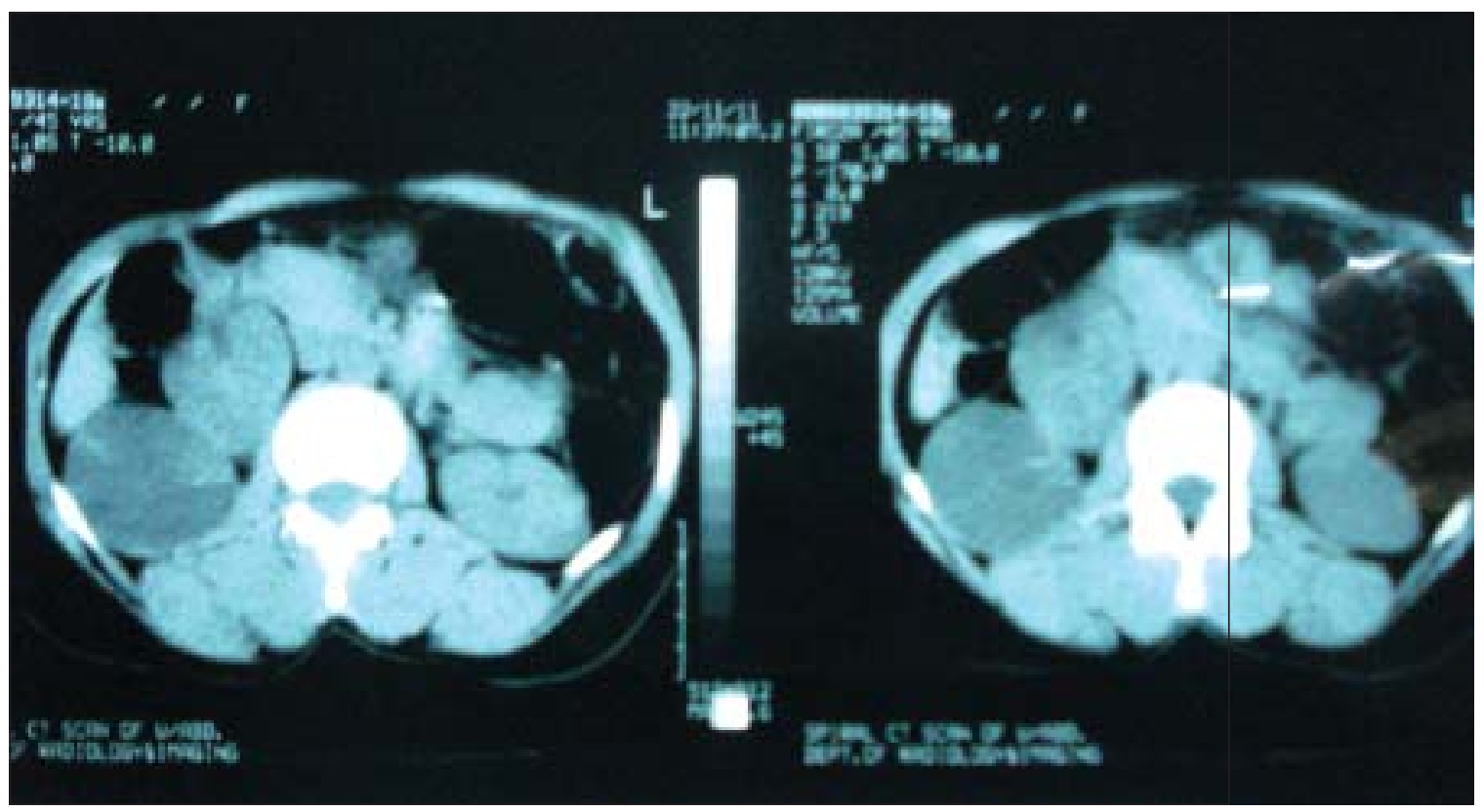

Fig.-1: Owing to the location of tumor the presumptive diagnosis was a neurogenic or fibrous tumor.

The right colon and right kidney was mobilized and $15 \mathrm{~cm} \times 10 \mathrm{~cm}$ in diameter mass was found. The mass was localized above the right psoas muscle and posteroinferior to the right kidney. The mass was completely resected and send for histopathology. Her post operative period was uneventful and the patient was discharged symptom free. The pathology report concluded the final diagnosis as degenerated schwannoma. Post operative follow up of 3 months has shown patient to be disease free clinically and on ultrasonographycally.

\section{Discussion:}

Schwannomas are usually benign tumors arising from the schwann cells of the peripheral nerve sheath ${ }^{11}$. These neoplasms are usually seen in adult population between the ages of 20 and 50 with a male/Female ratioof $2: 3^{7}$. Symptomatology of benign schwannomas is highly nonspecific and depends on the location and size of the lesion.

Retroperitoneal region is a rare location for schwannomas except in patients having Von Recklinghausen's disease. It is also noteworthy to mention that malignant degeneration particularly takes place in association with Von Recklinghausen's disease. In general, since the retroperitoneal space is rather large and flexible, the diagnosis of retroperitoneal schwannomas is often delayed, and the lesion reaches a significant size at the time of diagnosis usually more than $8 \mathrm{~cm}$ in diameter as seen in our cases. The most common symptoms are abdominal pain and distention. Depending on the location of the lesions, a variety of symptoms such as secondary hypertension, hematuria, and renal colic have also been reported ${ }^{12,13}$.

The differential diagnosis for retroperitoneal schwannomas includes other neurogenic tumors such as paraganglioma and pheochromacytoma as well as, liposarcoma and malignant fibrous histiocytoma. In addition to those, if the retroperitoneal schwannoma contains considerable amount of cystic degeneration, retroperitoneal cystic masses such as hematoma and lymphangioma should also be included in the diagnostic checklist ${ }^{14}$.

Although rare, malignant counterparts of schwannomas also exist. Detection of a malignant schwannoma is highly important, since it will affect the treatment strategy. From the radiologist's point of view, malignant schwannomas have irregular contour and tend to show invasion to the adjacent structures. Macroscopically, schwannomas are solitary, well circumscribed, firm, smooth-surfaced tumors. Because of their large size, these tumors are likely to manifest degenerative changes such as cysts and calcification ${ }^{15}$. The retroperitoneal lesion in our patient had regular borders without any sign of adjacent organ invasion, which were highly suggestive of a benign lesion radiologically. 
Most schwannomas are benign and malignant degeneration of schwannomas is extremely rare. Malignant degeneration particularly occurs is association with Von Recklinghausen's disease, as occurs in $5 \%$ to $18 \%$ of cases $^{16}$. To date, no standard diagnostic criteria or radiologic feature of malignant schwannomas have been described. Malignant schwannomas are commonly larger in size and they act as high-grade sarcomas with the possibility of producing local recurrence and distant metastasis. Typically, malignant schwannomas are diagnosed histopatologically after the surgical excision of a mass, with features of high mitotic rate, pleomorphism, and blood vessel invasion ${ }^{17}$.

Appropriate radiological evaluation is important both for diagnosis and management. Computed tomography typically shows well-defined mass with low or mixed attenuation and cystic and/or necrotic central areas. Cystic changes occur more commonly in retroperitoneal schwannomas (up to 66\%) than in other retroperitoneal tumors $^{18}$. Other degenerative changes, such as calcification and hemorrhage can be seen on CT. On MRI, schwannomas are seen as masses of low signal intensity on T1-weighted images and high signal intensity on T2-weighted images ${ }^{12,19}$. However these radiologic findings are characteristic but not specific of schwannomas and was noted in only $57 \%$ of the cases ${ }^{12}$. Depending on the cell density, the signal intensity on T2-weighted images may vary. CT-guided core biopsy and fine needle aspiration are not sufficient for the diagnosis of retroperitoneal schwannoma ${ }^{17}$. Degenerated areas can hinder the correct diagnosis and malignancy may be missed because of cellular pleomorphism and the presence of degenerative cells. Additionally, these procedures have the risks of hemorrhage, infection, and tumor seeding. Thus, many authors do not recommend CT-guided biopsy ${ }^{5,20}$.

Treatment depends solely on surgery.. Since local recurrence rate ranges from $16 \%$ to $54 \%$ after conservative approach, sacrifice of adjacent tissues and viscera may be considered for complete surgical excision $^{1,5}$. Dominguez et al. ${ }^{7}$ have reported recurrence in $16 \%$ in partial resection. Abernathey et al. did not approve partial resection of the tumor because of the consideration of local recurrence ${ }^{2}$. Giglio et al. proposed that even if the tumor were determined to be benign using frozen biopsy, the possibility of malignancy can not be excluded accurately ${ }^{10}$.

On the other hand, some authors believe that a simple enucleation or partial excision of the tumor is sufficient.
Because the benign nature of the disease, no increase in the size of schwannoma during a 6- and 14-year period and have been reported ${ }^{21}$. Is the size of the residual tumor after surgery the greatest factor that influence on the recurrence of schwannoma. Therefore, maximal removal as completely as possible of the operable part of tumor without severe hemorrhage and anticipated neurological injury level after surgery are two factors considered during the surgery $8,10,16,17,22$.

There are a few reported cases in which metastases occurred after resection of a histologically benign schwannoma ${ }^{19,25,23}$. The prognosis for retroperitoneal benign schwannoma is good. On the other hand, in malignant cases, extraction of the tumor and adjuvant radiation therapy or chemotherapy are required, and even in cases in which the appropriate treatments are administered, prognosis is poor, and it has been reported in one series that $62 \%$ of patients died. Furthermore in malignant schwannoma if extraction is insufficient local recurrence rate is high. White has reported that $60 \%$ died within 2 months, and Ghosh et al. have reported that in cases with a single lesion, the 5-year survival rate is $72.5 \%$, and in cases concomitant with von Recklinghausen's disease the 5-year survival rate is $30 \% 9,14,24,25$. Single therapy modality of malignant schwannomas has shown poor results.

\section{Conclusion:}

Retroperitoneal schwannoma is a rare type of retroperitoneal tomor often present as slow growing masses with difficult preoperative diagnosis. Surgery is the choice of treatment with a potential risk of severe bleeding and neurological deficit. Therefore careful preoperative evaluation and post operative monitoring is necessary.

\section{References:}

1. Li Q, Gao C, Juzi JT, Hao X: Analysis of 82 cases of retroperitoneal schwannoma. ANZ J Surg 2007; 77: 237240 .

2. Mason P. Experimental and spontaneous schwannomas (peripheral gliomas): part 1. Am J Pathol 1932; 8: 367370 .

3. Kang CM, Kim DH, Seok JY, Lee WJ. Laparoscopic resection of retroperitoneal benign schwannoma. J Laparoendosc Adv Surg Tech A 2008; 18: 411-416.

4. Micali S., Virgili G., Vespasiani G., Silecchia A., Alessandro P.D., Micali F. Benign schwannoma surrounding and obstruction the ureteropelvic junction. First case report. Eur Urol 1997; 32: 121-123. 
5. Sahin A, Kansu E, Sener C: The Tip Of The Iceberg: Mediastinal Schwannoma Presenting As Horner's Syndrome. J Neurol Sci [Turk] 2007; 24: 164-166

6. Sharma SK, Koleski FC, Husain AN, Ablama DM, Turk TM. Retroperitoneal schwannoma mimicking an adrenal lession. World J Urol 2002; 20: 232-233.

7. Theodosopoulos T, Stafyla VK, Tsiantoula P, Yiallourou A, Marinis A, Kondi-Pafitis A, et al. Special problems encountering surgical management of large retroperitoneal schwannomas. World J Surg Oncol 2008; 3: 6:107.

8. Girgin C, Ozkan U, Sezer A, Tugyan N. A. Large pelvic schwannoma causing bilateral hydronephrosis. Int J Urol 2003; 10: 616-618.

9. Chiang ER, Chang MC, Chen TH: Giant retroperitoneal schwannoma from the fifth lumbar nerve root with vertebral body osteolysis: a case report and literature review. Arch Orthop Trauma Surg 2009; 129: 495-499

10. Parfitt Jr HG, Hamonnd ME. Midletton Jr AW. Perirenal malignant schwannoma: a case report and review of literature. J Urol 1982; 128: 1299-1301.

11. Singh V; Kapoor R. Atypical presentation of benign retroperitoneal schwannoma: Report of three cases with review of literature. Int Urol and Nephrol 2005; 37: 547-549.

12. J. Cury, R. F. Coelho, and M. Srougi, "Retroperitoneal schwannoma: case series and literature review," Clinics, 2007; 62(3): 359-362. View at Scopus.

13. B. K. Goh, Y. M. Tan, Y. F. Chung, P. K. H. Chow, L. L. P. J. Ooi, and W. K. Wong, "Retroperitoneal schwannoma," American Journal of Surgery, vol. 2006; 192(1). 14-18. View at Publisher · View at Google Scholar · View at PubMed View at Scopus

14. C. S. Wong, T. Y. Chu, and K. F. Tam, "Retroperitoneal schwannoma: a common tumour in an uncommon site," Hong Kong Medical Journal, 2010; 16(1): 66-68. View at Scopus.
15. Daneshmand S, Youssefzadeh D, Chamie K, Boswell W, $\mathrm{Wu} \mathrm{N}$, Stein JP, et al. Benign retroperitoneal schawannoma: A case series and review of literature. Urology 2003; 62: 993-997.

16. Pellice C., Cosme M., Casalot J. Schwannoma of the spermatic cord. Actas Urol Esp 1994; 118: 328-330.

17. Chen KT, Latorrace R, Fubich D, Padgug A, Hafez G, Gilbert EF. Malignant schwannoma: A light microscopy and ultrastructural study. Cancer 1980; 45: 1583-1593

18. Takatera H, Takiuchi H, Namiki M, Takaha M, Ohnishi S, Sonoda T. Retroperitoneal schwannoma. Urology. 1986; 28: 529-531.

19. Ohigashi T, Nonaka S, Nakanoma T, Ueno M, Deguchi N. Laparoscopic treatment of retroperitoneal benign schwannoma. Int J Urol 1999; 6: 100-103

20. Nakamura M, Takayama T, Takayasu K, Shimada K, Yamamoto J, Kosuge T, et al. Retroperitoneal schwannoma mimicking hepatic tumor in the caudade lobe. Jpn J Clin Oncol. 1997; 27: 282-284.

21. Regan JF, Juler GL, Schmutzer KJ: Retroperitoneal neurilemoma. Am J Surg 1977; 134: 140-145.

22. Song JY, Kim SY, Park EG, Kim CJ, Kim do G, Lee HK, Park IY. Schwannoma in the retroperitoneum. J Obstet Gynaecol Res 2007; 33: 371-375.

23. Yoshino T, Yoneda K. Laparoscopic resection of a retroperitoneal ancient schwannoma: a case report and review of the literature. Anticancer Res. 2008; 28: 28892891.

24. Kishi Y, Kajiwara S, Seta S, Kawauchi N, Suzuki T, Sasaki K. Retroperitoneal schwannoma misdiagnosed as a psoas abscess: report of case. Surg Today 2002; 32: 849-852.

25. Schindler OS, Dixon JH, Case P. Retroperitoneal giant schwannomas: report on two cases and review of the literature. J Orthop Surg 2002; 10: 77-84 